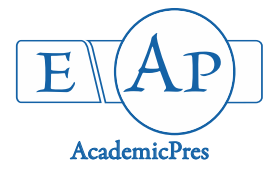

\title{
Evaluation of Various Biological Activities of Endemic Sideritis libanotica Extracts
}

\section{Mehmet ATAS $^{1}$, Nuraniye ERUYGUR ${ }^{2}$, Fazli SOZMEN ${ }^{3}$, Mustafa ERGUL ${ }^{4}$, Merve ERGUL ${ }^{5}$, Huseyin Askin AKPULAT ${ }^{6}$, Esra UCAR ${ }^{7 *}$}

\author{
${ }^{I}$ Sivas Cumburiyet University, Faculty of Pharmacy, Pharmaceutical Microbiology Department, 58140, Sivas, Turkey; atasmehmet@gmail.com \\ ${ }^{2}$ Selcuk University, Department of Pharmacognosy, Faculty of Pharmacy, Konya, Turkey; neruygur@cumburiyet.edu.tr \\ ${ }^{3}$ Sivas Cumburiyet University, Faculty of Engineering, Nanotechnology Engineering Department, 58140, Sivas, Turkey; fsozmen@hotmail.com \\ ${ }^{4}$ Sivas Cumburiyet University, Faculty of Pharmacy, Biochemistry Department, 58140, Sivas, Turkey; m.ergul@yahoo.com.tr \\ ${ }^{5}$ Sivas Cumburiyet University, Faculty of Pharmacy, Pharmacology Department, 58140, Sivas, Turkey; mergulmerve@gmail.com \\ ${ }^{6}$ Sivas Cumburiyet University, Department of Biology, Faculty of Education, Sivas, Turkey; hakpulat@cumburiyet.edu.tr \\ ${ }^{7}$ Sivas Cumburiyet University, Vocational School, Medicinal and Aromatic Plant Department, 58140, Sivas, \\ Turkey; eucar@cumburiyet.edu.tr (*correspondingauthor)
}

\begin{abstract}
In recent years, using of plants to develop combine therapies for treatment of certain diseases such as cancer, Alzheimer's disease, and diabetes mellitus is extremely plausible approach. Perhaps, the definitive treatment of some of these diseases is hidden in the complex content of a plant in nature. Thus, in the present study, we decided to determine the biological activities of methanol and water extracts of the endemic Sideritis libanotica. To the best of our knowledge, the present study is the first investigation on antioxidant, enzyme inhibitory activity, antimicrobial activity, and in vitro cytotoxicity of $S$. libanotica. According to results, while the methanol extract shows better anti-cholinesterase, $\alpha$-glucosidase, and $\alpha$-amylase inhibition activity and cytotoxicity than the water extract, the tyrosinase inhibitory activity of the water extract was found to be better than the methanol extract. This study provides valuable information on how the biological activity of endemic $S$. libanotica changes in different solvent extractions such as water and methanol.
\end{abstract}

Keywords: antioxidants; biological activities; enzyme inhibition; Sideritis libanotica

Abbreviations: ABTS - 2,2'-Azino-bis-(3-ethylbenzothiazoline-6-sulphonic acid); AChE - Acetylcholinesterase; BHT - Butil Hidroksi Toluen; BuChE - Butyrylcholinesterase; CFU - Colony-forming units; ChEI - Cholinesterase inhibitors; DMEM Dulbecco's modified eagle medium; DMSO - Dimethyl sulfoxide; DPPH - 2,2-Diphenyl-1-picrylhydrazyl; ELISA - Enzymelinked immunosorbent assay; GC-MS - Gas Chromatography-Mass Spectrometry; MIC - Minimum inhibitory concentration; PBS - Phosphate buffered saline; TTC - 2, 3, 5-Triphenyltetrazolium chloride; USA - United States of America; XTT - (2,3bis-(2-methoxy-4-nitro-5-sulfophenyl)-2H-tetrazolium-5-carboxanilide).

\section{Introduction}

Sideritis species have been widely utilized against gastrointestinal disorders and common colds in folk medicine. So moreover, the pharmacological activities of Sideritis species have been attracted many attentions due to their traditional medicine usage and consuming as herbal tea in the world. There are 46 species in the genus Sideritis in flora of Turkey and 31 of them are endemic (Davis, 1982; Davis, 1988; Tepe et al., 2006; Demirtas et al., 2011). Sideritis species rich in essential oil, terpenes and flavonoids have been widely consumed for centuries to relieve cold symptoms, including fever, flu, sore throat, bronchitis, and to treat of gastrointestinal disorders such as stomach ache, indigestion and flatulence (Schmeda-Hirschmann and Yesilada, 2005; González Burgos et al., 2011; Korkmaz et al., 2017a; Korkmaz et al., 2017b;) It has been reported that some Sideritis species such as S. lycia and S. libanotica are feared to be in the list of endangered species because of their extensively collection from natural habitat (Kargioglu et al., 2008; Polat and Satil, 2012; Dincer et al., 2017).

Natural antioxidants especially exist in plants have been extensively studied owing to their beneficial effects on human health. Besides these effects, antioxidants are able to 
maintain nutritional quality and extend the shelf life of food products because of their ability to control rancidity development and retard the formation of toxic oxidation products (Charles, 2013; Sama et al., 2014; Patra et al., 2016; Yashin et al., 2017).

Acetylcholinesterase (AChE) and butyrylcholinesterase $(\mathrm{BuChE})$ are two types of enzymes that form cholinesterase enzymes. Despite the fact that the $\mathrm{AChE}$ and $\mathrm{BuChE}$ resemble each other more than $50 \%$, their importance and location are significantly different in the body (Giacobini, 2003; Pohanka, 2011). Because the main function of AChE is rapid splitting of acetylcholine and terminating cholinergic neurotransmission, it is mainly found in many types of conducting tissue such as nerve, muscle, central and peripheral tissues (Koelle, 1954; Chacko and Cerf, 1960; Colović, 2013). There are two basic types of AChE inhibitors, which are either reversible or irreversible. These inhibitors are used in the diagnosis and/or treatment of some diseases, one of which is Alzheimer's disease (AD). There is no cure for $\mathrm{AD}$, but cholinesterase inhibitors (ChEI) have been used the treat symptoms related to memory, thinking, language, judgment and other thought processes (Koelle, 1954; Chacko and Cerf, 1960; Giacobini, 2004; Lane et al., 2006; Čolović, 2013).

Diabetes mellitus (DM) is one of the most prevalent diseases worldwide and millions of people are suffering from this disease. Although glucosidase inhibitors have been used therapeutically since the 1990s, these drugs possess several side effects. For this reason, there is an extremely intensive effort to discover inhibitors with natural and less side effects (Proenca et al., 2017; Tundis et al., 2010). $\alpha$-glucosidase and $\alpha$-amylase are the main starch digestive enzymes and while the $\alpha$-glucosidase catalyzes the hydrolytic reaction to liberate $\alpha$-glucose from the non-reducing end of the substrate, $\alpha$ amylase catalyzes the hydrolysis of $\alpha$-1,4-glucan bonds in starch maltodextrin and maltooligosaccharides (Truscheit $e t$ al., 1981; Svensson, 1988; Henrissat, 1998; Kimura, 2000; Yamamoto, 2004; Tundis et al., 2010). Today cancer is one of the most dangerous diseases in the world. Therefore, a lot of effort is spent to find a cure for cancer and, the discovery of natural anticancer products as supportive therapy in cancer treatment is of great importance.

The main purpose of this study is to determine the biological activities of methanol and water extracts of the endemic $S$. libanotica. Antioxidant, antimicrobial, cytotoxicity and various enzyme inhibition activities of these two extracts have been studied. Additionally, we identified and compared the chemical content of the extracts. To the best of our knowledge, the present study is the first investigation on antioxidant, enzyme inhibitory activity, antimicrobial activity and in vitro cytotoxicity of $S$. libanotica.

\section{Materials and Methods}

\section{Preparation of extracts}

The aerial parts of plant were milled with a grinder after dried up to constant weight in shade. Dry plant parts were ground with blender (Blue house). Ten (10) g of plant was soaked in $50 \mathrm{~mL}$ of deionized water for $24 \mathrm{~h}$ with intermittent shaking. At the end of extraction, it was filtrated by No. 1 Whatman filter paper. The filtrate was concentrated to dryness under reduced pressure with rotary evaporator at $40{ }^{\circ} \mathrm{C}$ and this was repeated for three times. The obtained extracts were analyzed by using GC-MS (Sacchetti, 2005). The same procedure was followed for methanol extraction.

\section{In vitro antioxidant activity}

The antioxidant activity of the methanol and water extracts of S. libanotica leaves was tested using different methods namely as DPPH, ABTS radical scavenging activity, total phenol, and total flavonoid content method.

\section{Determination of DPPH radical scavenging activity}

The free radical scavenging activity by methanol extracts was performed according to the method reported by MiserSalihoglu et al. (2013) $150 \mu \mathrm{L}$ of the extract with different concentration was mixed with $50 \mu \mathrm{L}$ of $1.0 \times 10^{-3} \mathrm{M}$ freshly prepared DPPH methanol solution in 96 well plate. Methanol was used as control of the experiment. After 30 min of incubation at $25^{\circ} \mathrm{C}$, the reduction of the DPPH free radical was measured reading the absorbance at $517 \mathrm{~nm}$ with microplate reader (Epoch, USA). BHT used as positive controls and the percent inhibition was calculated with the following equation:

$\%$ Inhibition $=[$ Absorbance of control - Absorbance of test sample / Absorbance of control] $\times 100$

\section{Determination of ABTS radical scavenging activity}

For determining of ABTS radical scavenging activity of the extracts, followed by the method of Re et al. (1999) with slight modification. The stock solution of ABTS was made by reacting $7 \mathrm{mM}$ ABTS solution with $2.4 \mathrm{mM}$ of potassium persulfate solution in equal volume for $16 \mathrm{~h}$. working solution was then prepared by diluting the stock ABTS solution with methanol to give an absorbance of 0.7 \pm 0.02 units at $734 \mathrm{~nm}$ using a microplate reader (Epoch, USA). In each experiment, the ABTS solution was prepared freshly. $50 \mu \mathrm{L}$ of extract was mixed with $150 \mu \mathrm{L}$ ABTS working solution and stand for $10 \mathrm{~min}$ at dark place. All the analyses were conducted in triplicate and the results expressed as mean \pm standard deviation. Appropriate blanks (methanol) and standard (BHT) were run simultaneously.

\section{Determination of total phenolic contents (TPC)}

To measure the total phenolic content in the extracts, spectrophotometric Folin-Ciocalteu method was used as previously described by Clarke et al. (2013) with slight modification. Briefly, $20 \mu \mathrm{L}$ of extract in DMSO was mixed with $100 \mu \mathrm{L}$ freshly $1 / 10$ diluted F-C reagent with distilled water. After five min, the solution was mixed with $80 \mu \mathrm{L}$ of $7.5 \% \mathrm{Na}_{2} \mathrm{CO}_{3}$ solution, and incubated for $30 \mathrm{~min}$ at $25^{\circ} \mathrm{C}$. The measurement of absorbance was done at $650 \mathrm{~nm}$ in a microplate reader (Epoch, USA). All the analyses were performed in triplicate and the results expressed as mean \pm standard deviation. Appropriate blanks (DMSO) and standard (gallic acid in DMSO) were run simultaneously, after which the total phenolic content (TPC) was calculated as milligrams gallic acid equivalents per gram of dry extract. 
212

\section{Estimation of total flavonoid content (TFC)}

For determination of total flavonoid content, the aluminum chloride colorimetric method was used as previously described by Molan and Mahdy (2014) using catechin as the reference standard. Briefly, $25 \mu \mathrm{L}$ of 1 $\mathrm{mg} / \mathrm{mL}$ test sample solution, $100 \mu \mathrm{L}$ of dd. $\mathrm{H}_{2} \mathrm{O}$ and $7 \mu \mathrm{L}$ of $5 \% \mathrm{NaNO}_{2}$ were mixed together in 96-well plates. After 15 min of incubation at room temperature, $7 \mu \mathrm{L}$ of $10 \% \mathrm{AlCl} 3$ was added. After $5 \mathrm{~min}, 50 \mu \mathrm{L}$ of $1 \mathrm{M} \mathrm{NaOH}$ and $60 \mu \mathrm{L}$ of distilled water were added to each well. Then the absorbance was measured at $490 \mathrm{~nm}$ in a microplate reader (Epoch, USA). All determinations were carried out in triplicates. The content of total flavonoids was expressed as $\mathrm{mg}$ of catechin equivalent per $\mathrm{g}$ of dry weight of extract.

\section{Enzym activities}

Acetylcholinesterase/butyrylcholinesterase inhibition assay

Experiment was carried out according to the Ellman $e t$ al. (1961) method. The assay was performed in the following way. The mixture consisted of $20 \mu \mathrm{L}$ of test sample/reference standard of various concentrations, 140 $\mu \mathrm{L}$ of $0.1 \mathrm{mM}$ phosphate buffer ( $\mathrm{pH} 6.8$ ), $10 \mu \mathrm{L}$ of $3 \mathrm{mM}$ 5,5'-dithio-bis-nitrobenzoic acid (DTNB) and $20 \mu \mathrm{L}$ of enzyme $(0.22 \mathrm{U} / \mathrm{mL}$ for acetylcholinesterase/ $0.1 \mathrm{U} / \mathrm{mL}$ for butyrylcholinesterase) prepared in phosphate buffer was incubated for $5 \mathrm{~min}$ at $25^{\circ} \mathrm{C}$. Following preincubation, 10 $\mu \mathrm{L}$ of the substrate $(0.71 \mathrm{mM}$ acetylthiocholine iodide/0.2 $\mathrm{mM}$ butyrylthiocholine chloride in phosphate buffer) was added to start the reaction and incubated again for $10 \mathrm{~min}$. The developed yellow color was measured at $412 \mathrm{~nm}$ (Epoch, USA). Galanthamine was used as positive control.

\section{a-Glucosidase inhibition activity}

$\alpha$-Glucosidase inhibition method was followed by Kumar et al. (2012). Acarbose was used as a positive control, while phosphate buffer was used as negative control in place of sample. Each concentration was carried out in triplicate. $25 \mu \mathrm{L}$ of sample solution diluted with buffer was mixed with $25 \mu \mathrm{L}$ of $\alpha$-glucosidase $(0.5 \mathrm{U} / \mathrm{mL})$, incubate for about $10 \mathrm{~min}$ at $25^{\circ} \mathrm{C}$. Then $25 \mu \mathrm{L}$ of $0.5 \mathrm{mM} 4$-nitrophenyl- $\beta$ $\mathrm{D}$-glucoronide (pNPG) was added to each well as substrate and incubated further $30 \mathrm{~min}$ at $37^{\circ} \mathrm{C}$. After incubation period, $100 \mu \mathrm{L}$ of $0.2 \mathrm{M}$ sodium carbonate was added to terminating the reaction and the absorbance was read at 405 $\mathrm{nm}$.

\section{$\alpha$-Amylase inbibition activity}

$\alpha$-Amylase inhibition method was followed by Kumar $e t$ al. (2013). Acarbose was used as a positive control, while phosphate buffer (0.02 M PBS, pH 6.9) was used as negative control in place of sample. Each sample was carried out in triplicate with different concentrations. The reaction mixture containing $50 \mu \mathrm{L}$ of sample solution diluted with buffer, $25 \mu \mathrm{L}$ of $\alpha$-amylase from porcine pancreases $(0.5$ $\mathrm{mg} / \mathrm{mL}$ ) incubated for about $10 \mathrm{~min}$ at $25^{\circ} \mathrm{C}$. Then $50 \mu \mathrm{L}$ of $0.5 \%$ starch solution ( $\mathrm{w} / \mathrm{v})$ prepared freshly was added to each well as substrate and incubated further $10 \mathrm{~min}$ at $25{ }^{\circ} \mathrm{C}$. After incubation period, $100 \mu \mathrm{L}$ of $1 \% 3$, 5dinitrosalicylic acid (DNS) color reagent was added as color reagent and heated at water bath for $10 \mathrm{~min}$. The absorbance was read at $540 \mathrm{~nm}$.

\section{Tyrosinase inbibition activity}

Tyrosinase inhibitory activity was determined by the 96well plate spectrophotometrically as described by Jeong $e t a l$. (2009) with slight modifications. Kojic acid was used as a positive control, while phosphate buffer (0.1 M PBS, pH 6.8) was used as negative control in place of sample. Each sample was performed in triplicate. Briefly, $20 \mu \mathrm{L}$ of sample solution with different concentrations was added to a 96well microplate and mixed with $20 \mu \mathrm{L}$ of tyrosinase from mushrooms $(250 \mathrm{U} / \mathrm{mL})$. After $10 \mathrm{~min}$ of incubation at $25^{\circ} \mathrm{C}, 20 \mu \mathrm{L}$ of $3 \mathrm{mM} \mathrm{L}$-tyrosine was added to each well as substrate and incubated further $30 \mathrm{~min}$ at $25^{\circ} \mathrm{C}$. After incubation period, the absorbance of the reaction mixture was read at $492 \mathrm{~nm}$ in a microplate reader (Epoch, USA).

Determination of minimum inbibitory concentration (MIC) of Sideritis libanotica extracts

The minimum inhibitory concentration (MIC) of the S. libanotica water and methanol extracts against bacteria and fungus was carried out by broth microdilution method using 96-well cell culture plates (Eloff, 1998). For this purpose, Escherichia coli (ATCC 25922), Staphylococcus aureus (ATCC 29213), Pseudomonas aeruginosa (ATCC 27853), Bacillus cereus (ATCC 11778), Candida albicans (ATCC 10231) and Candida tropicalis (DSM 11953) strains were used. The extracts were dissolved in Dimethyl Sulfoxide (DMSO) at $50 \mathrm{mg} / \mathrm{mL}$ concentration. Ten (10) $\mu \mathrm{l}$ samples were added in the first line of a microtiter plate which was diluted with $90 \mu \mathrm{l}$ broth. Next, $50 \mu \mathrm{l}$ sample was added in the second line of a microtiter plate which was serially diluted two-fold with broth. Concentration of the extracts in wells ranged from 2.5 to $0.004 \mathrm{mg} / \mathrm{mL}$. Column 11 and 12 was used as a negative control for medium sterility (no microorganism) and positive growth control (no extracts), respectively.

Mueller Hinton Broth (Accumix ${ }^{\circ}$ AM1072) was used for bacteria and Saboraud Dekstroz Broth (Himedia ME033) for Candida. Bacteria and fungi suspension (50 $\mu \mathrm{L}$ ) were added on prepared samples. Final inoculum size was $5 \times 10^{5} \mathrm{CFU} / \mathrm{mL}$ at bacteria and $0.5-2.5 \times 10^{3} \mathrm{CFU} / \mathrm{mL}$ at Candida every well (CLS, 2002; CLSI, 2012). Samples, which added bacteria, were incubated at $37^{\circ} \mathrm{C}$ and samples that added Candida were incubated at $35^{\circ} \mathrm{C}$ between $16-24$ hours. Afterwards, $\quad 40 \quad \mu \mathrm{L} \quad(2 \quad \mathrm{mg} / \mathrm{mL}) \quad 2,3,5-$ Triphenyltetrazolium chloride (TTC) (Merck, Germany) was added to each well to indicate microbial growth. The microtiter plates were further incubated at $37^{\circ} \mathrm{C}$ for $2 \mathrm{~h}$.

\section{In vitro cytotoxicity assay \\ Cell lines and reagents}

Human breast adenocarcinoma cell line, MDA-MB-231 (HTB-26) and mouse fibroblast cells, L929 (CRL-6364) were purchased from American Type Culture Collection (ATCC, Manassas, VA). Fetal bovine serum (FBS), Dulbecco's modified Eagle's medium (DMEM), and sterile phosphate buffer saline (PBS) were purchased from PAA Ltd. (France). Trypsin-EDTA was supplied from Biological Industries Ltd. (Haemek, Israel). L-glutamine-penicillinstreptomycin solution was from Sigma-Aldrich (Steinheim am Albuch, Germany). XTT reagent (2,3-bis-(2-methoxy4-nitro-5-sulfophenyl)-2H-tetrazolium-5-carboxanilide) was purchased from Roche Diagnostic. 


\section{Cell culture}

The cytotoxicity of the S. libanotica methanol and water extracts was tested against MDA-MB-231 and L929 cell lines. Both cell lines were cultured in DMEM containing with $10 \% \mathrm{FBS}, 1 \% \mathrm{~L}$-glutamine, $100 \mathrm{IU} / \mathrm{mL}$ penicillin and $10 \mathrm{mg} / \mathrm{mL}$ streptomycin in $25 \mathrm{~cm}^{2}$ polystyrene flasks and maintained in a humidified atmosphere with $5 \% \mathrm{CO}_{2}$ at $37{ }^{\circ} \mathrm{C}$. Growth and morphology were monitored, the culture medium was changed every two days, and cells were passaged when they had reached $80-90 \%$ confluence.

\section{Cell viability assay}

The antiproliferative activity of the $S$. libanotica methanol and water extracts was evaluated using the XTT colorimetric assay. The extracts were dissolved in DMSO and diluted in DMEM prior to treatment. Initially, cancer and control cells were seeded at a density of $1 \times 10^{4}$ cells per well in 96-well culture plates in $100 \mu \mathrm{L}$ of culture medium and were allowed to attach overnight before treatment. The next day, these cells were treated with serial concentrations $(0.0625,0.125,0.25,0.5,1 \mathrm{mg} / \mathrm{mL})$ of S. libanotica for $24 \mathrm{~h}$. Besides, non-treated cells and cells treated with DMSO $(0.5 \%)$ were used as negative control and solvent control respectively. After that, the treatment medium was removed and wells were washed twice with $200 \mu \mathrm{L}$ phosphate buffered saline (PBS). At the end of these periods, for determination of living cells, $100 \mu \mathrm{L}$ DMEM without phenol red and $50 \mu \mathrm{L}$ XTT labeling mixture were added to each well and then the plates were incubated for another 4 h. The absorbance of XTT-formazan was measured using micro plate reader (Thermo, Germany) at $450 \mathrm{~nm}$ against the control (the same cells without any treatment). All experiments were performed in three independent experiments and the cell viability was expressed in \% related to control ( $100 \%$ of viability).

\section{Statistical analysis}

Statistical analysis was performed using the Graphpad prism 7.0 (USA, Sandiago) software. On antioxidant, antiAchE, Anti-BchE, $\alpha$-glucosidase and $\alpha$-amylase and tyrosinase inhibitory activity results were expressed as mean \pm standard deviation (SD) of the mean of three parallel measurements. Data were analyzed by one-way analysis of variance (ANOVA) followed by Dunnett's Multiple Comparison test or Tukey's Multiple Comparison test. The $\mathrm{P}<0.05$ was considered to indicate statistical significance.

\section{Results and Discussion}

The chemical contents of the extracts were determined by using the GC-MS (Table 1). As seen in Table 1, the chemical contents of the methanol and water extracts showed significant differences. In fact, this difference accounts for the significant changes in the biological activities of the extracts. These changes in biological activity are briefly discussed below.

\section{Antioxidant activity}

The in vitro antioxidant activities including total phenolic and flavonoid contents, DPPH and ABTS radical scavenging activities of $S$. libanotica in the methanol and water extract were investigated and compared with the standard antioxidant compounds BHA and gallic acid.

\section{Totalphenolic and flavonoid content}

As shown in Table 2, the total phenolic content values for the water and methanol extract of $S$. libanotica range from $62.79 \pm 1.06$ to $111.53 \pm 8.3 \mathrm{mg}$ gallic acid equivalents (GAE)/g dried extract, while their total flavonoid content values range from $25.45 \pm 3.18$ to $43.56 \pm 0.60 \mathrm{mg}$ catechine equivalents (CE)/g dried weight of extract. The methanol extract possess higher TPC and TFC values than the water extract. In other words, the methanol extracts have more phenolic compounds and flavonoids than the water extract. Quantitative analysis of total phenolics and flavonoids in different extracts (ethanol, diethylether, ethyl acetate and n-butanol) of Sideritis scardica was performed previously by Tadic et al. (2012), and the ethyl acetate extract was found contain highest amount of total phenolic (345.6 mg GAE/g DW) and flavonoid content (1.1\%). In another study by Deveci et al. (2017) the total phenol and flavonoid content of Sideritis pisidica Boiss. Hexan, methanol and acetone extracts were found between 20.40 $100.24 \mathrm{mg}$ pyrocatechol equivalents per gram and 30.66 $43.75 \mathrm{mg}$ quercetin equivalents per gram, respectively (Deveci et al., 2017). According to these results, the total phenol and flavonoid content of S. libanotica was found between those results.

\section{$D P P H$ and $A B T S$ radical scavenging activity}

In terms of DPPH and ABTS radical scavenging activity, the extracts showed a concentration-dependent inhibitory activity and results are given in Table 2 . The methanol extract exhibited the highest overall DPPH and ABTS free radical scavenging capacity, the IC 50 value was determined as $49.62 \pm 3.55 \mathrm{\mu g} / \mathrm{mL}$ and $39.52 \pm 1.27$ $\mu \mathrm{g} / \mathrm{mL}$, respectively. In addition, extremely high DPPH and ABTS radical scavenging activity difference is observed between the methanol and the water extracts probably due to the excess of soluble in methanol extracts.

\section{Enzym activities}

\section{Anti-cholinesterase activity}

When the anti-acetylcholinesterase and antibutyrylcholinesterase inhibition activities of the methanol and water extract of S. libanotica were compared with each other, the methanol extract was found to be more active than the water extract. As it seen presented in Table 2, the methanol and water extract displayed $73.45 \pm 3.50 \%$ and $65.58 \pm 2.47 \%$ inhibition on acetylcholinesterase and 31.48 $\pm 3.74 \%$ and $27.6 \pm 1.06 \%$ butyrylcholinesterase inhibition activity. The high amounts of phenolic and flavonoids found in the methanol extract may be responsible for the anticholinesterase activity. Although the methanol extract shows strong anti-acetylcholinesterase and antibutyrylcholinesterase inhibition activity, it still has lower activity values than the reference drug.

\section{$\alpha$-Glucosidase and $\alpha$-Amylase inhibition activity}

The inhibitory activities of the methanol and water extract of $S$. libanotica were evaluated against $\alpha$-glucosidase and $\alpha$-amylase enzyme (Table 2 ) in comparison with the positive control drug acarbose. Previous studies reported that the flavonoids with hydroxyl group have the inhibition activity to $\alpha$-glucosidase enzyme (Salah et al., 2017). 
214

Table 1. Chemical composition of water and methanol extracts of S. libanotica

\begin{tabular}{|c|c|c|c|}
\hline Chemical Component & RT & Water & Methanol \\
\hline Cyanomethyl 2-chloroethyl sulfide & 4.294 & 1.17 & \\
\hline 1H-Pyrrole, 1-methyl- & 4.695 & 0.52 & \\
\hline Tetrahydrothiophen-3-one & 5.433 & & 0.11 \\
\hline 2-Furanmethanol (CAS) & 6.726 & 0.20 & \\
\hline 4-Cyclopentene-1,3-dione & 7.521 & 0.37 & \\
\hline isomeric dihydro - methyl - furanone & 8.980 & 2.41 & \\
\hline 1,2-Cyclopentanedione & 9.026 & & 0.28 \\
\hline Phenol (CAS) & 11.406 & 0.25 & \\
\hline 2,4,6(1H,3H,5H)-Pyrimidinetrione (CAS) & 14.250 & 0.49 & \\
\hline Phenol, 2-methoxy-(CAS) & 15.046 & 0.27 & \\
\hline 4H-Pyran-4-one, 2,3-dihydro-3,5-dihydroxy-6-methyl- & 16.768 & 1.57 & \\
\hline 1,4:3,6-Dianhydro-. alpha. -d-glucopyranose & 18.668 & & 0.12 \\
\hline 2,3-DIHYDRO-BENZOFURAN & 19.034 & & 0.20 \\
\hline 2-Methoxy-4-vinylphenol & 22.605 & & 0.59 \\
\hline 4-vinyl-2-methoxy-phenol & 22.622 & 1.89 & \\
\hline $\mathrm{n}$-Tridecan-1-ol & 28.275 & & 2.05 \\
\hline 1-Dodecanol & 28.281 & 7.69 & \\
\hline Phenol, 2,4-bis(1,1-dimethylethyl) - (CAS) & 29.379 & & 0.75 \\
\hline Phenol, 2,4-bis(1,1-dimethylethyl) & 29.391 & 3.25 & \\
\hline Megastigmatrienone & 32.166 & 0.89 & \\
\hline Cyclododecane & 33.470 & 4.62 & \\
\hline Dodecyl acrylate & 33.476 & & 4.94 \\
\hline Lidocaine & 37.476 & & 0.42 \\
\hline Hexadecanoic acid, methyl ester & 37.739 & 5.89 & 0.67 \\
\hline n-Hexadecanoic acid & 38.380 & 0.93 & \\
\hline 1,15-Hexadecadiene & 39.971 & & 0.45 \\
\hline 6,9,12-Octadecatrienoic acid, methyl ester & 40.217 & 1.57 & \\
\hline 9,12-Octadecadienoic acid (Z, Z)-, methyl ester (CAS) & 40.457 & 5.51 & \\
\hline 10-Octadecenoic acid, methyl ester (CAS) & 40.543 & 3.61 & \\
\hline Methyl stearate & 40.920 & 1.25 & \\
\hline 3-Ethyl-4,6-dimethylpyrano[3,2-g] chromene-2,8-dione & 43.570 & & 0.55 \\
\hline 9-Octadecenamide, (Z)- & 44.394 & 18.38 & \\
\hline Octadecane & 46.047 & & 0.66 \\
\hline 4-Hydroxymethyl-3-(2',4'-dimethyl-7'-indolyl)-2-methylindole & 47.541 & & 64.98 \\
\hline
\end{tabular}

Table 2. In vitro antioxidant and enzyme inhibitory activities (\%) of the methanol and water extracts from aerial parts of S. libanotica

\begin{tabular}{|c|c|c|c|c|c|c|c|c|c|}
\hline \multirow{2}{*}{ Extracts } & \multirow{2}{*}{$\begin{array}{c}\text { DPPH Radical } \\
\text { Scavenging } \\
\text { Activity }\end{array}$} & \multirow{2}{*}{$\begin{array}{c}\text { ABTS Radical } \\
\text { Scavenging } \\
\text { Activity }\end{array}$} & \multirow{2}{*}{$\begin{array}{c}\text { Total } \\
\text { Phenolic } \\
\text { Content }\end{array}$} & \multirow{2}{*}{$\begin{array}{c}\text { Total } \\
\text { Flavonoid } \\
\text { Content }\end{array}$} & \multicolumn{2}{|c|}{$\begin{array}{c}\text { Anticholinesterase } \\
\text { Activity* }\end{array}$} & \multicolumn{2}{|c|}{ Antidiabetic Activity* } & \multirow{2}{*}{$\begin{array}{c}\text { Skin } \\
\text { Whitening } \\
\text { Tyrosinase }\end{array}$} \\
\hline & & & & & AChE & BChE & $\begin{array}{c}\text { a- } \\
\text { Glucosidase }\end{array}$ & a-Amylase & \\
\hline Methanol & $49.62 \pm 3.55$ & $39.52 \pm 1.27$ & $111.53 \pm 8.3$ & $43.56 \pm 0.60$ & $73.4 \pm 3.50$ & $31.4 \pm 3.74$ & $32.87 \pm 0.89$ & $36.34 \pm 3.91$ & $58.21 \pm 2.72$ \\
\hline Water & $685.81 \pm 1.25$ & $211.96 \pm 1.41$ & $62.79 \pm 1.06$ & $25.45 \pm 3.18$ & $65.5 \pm 2.47$ & $27.6 \pm 1.06$ & $25.93 \pm 1.61$ & $14.08 \pm 1.71$ & $75.32 \pm 3.25$ \\
\hline \multicolumn{10}{|l|}{ Reference Drugs } \\
\hline Galanthamine & & & & & $93.87 \pm$ & $89.89 \pm$ & & & \\
\hline Hydrobromide & & & & & 0.56 & 0.01 & & & \\
\hline Acarbose & & & & & & & $57.56 \pm 0.52$ & $58.40 \pm 0.63$ & \\
\hline
\end{tabular}


The same with anticholinesterase activity, the methanol extract demonstrated higher inhibitory activity both to $\alpha$ glucosidase $(32.87 \pm 0.89 \%)$ and $\alpha$-amylase $(36.34 \pm 3.91 \%)$ enzyme than the water extract. However, the activity was lower than the reference drug acarbose $(57.56 \pm 0.52 \%$ and $58.40 \pm 0.63 \%$, respectively).

\section{Tyrosinase inbibition activity}

In recent years, tyrosinase inhibitors have gained importance due to the effect of tyrosinase enzyme on human health, browning of foods and the role of determine skin tone. In the method used, L-tyrosine was used as the substrate to determine the phenolase activities of mushroom tyrosinase, while kojic acid was used as the reference drug. The tyrosinase inhibitory activities of the methanol and water extracts of S. libanotica are presented in Table 2 as percentage at the concentration of $2 \mathrm{mg} / \mathrm{mL}$. Our results revealed that the water extract showed a good tyrosinase inhibitory activity than the methanol extract, however, it was higher than the kojic acid which was used as a positive control showed an inhibition level of $56.42 \%$. Deveci et al reported that, the methanol $(23.29 \pm 0.56 \%)$ and acetone $(15.66 \pm 0.11 \%)$ extracts of Sideritis stricta were found to be low active against tyrosinase, while the hexane and water extracts were found to be inactive (Deveci $e t a l$., 2018).

To the best of our knowledge, the present study is the first investigation on antioxidant and enzyme inhibitory activity of $S$. libanotica. The obtained results showed that the methanol extract that possessed better antioxidant, antiacetylcholinesterase effects. In addition, the methanol extract showed higher amount of total phenolic and flavonoid content than water extract. Generally, the higher antioxidant activity of methanol extract of S. libanotica extract than water extract can be correlated primarily with their higher amount of total phenolic and flavonoid contents. Therefore, further phytochemical and bioactivityguided isolation of $S$. libanotica could be carried out to identify their active compounds.

\section{Antimicrobial activity}

The antimicrobial activity of plant extracts are accepted significant if the MIC value is $0.1 \mathrm{mg} / \mathrm{ml}$ or lower, moderate if $0.1<$ MIC $\leq 0.625 \mathrm{mg} / \mathrm{ml}$ and weak if MIC $>0.625$ $\mathrm{mg} / \mathrm{ml}$ (Kuete, 2010; Awouafack et al., 2013). The results of the microdilution broth assay showed that water extracts of $S$. libanotica appeared to have weak antimicrobial activity against all the tested microorganisms (MIC values of 2.5 . $>2.5 \mathrm{mg} / \mathrm{mL}$ ). MIC values of the methanol extract against S.aureus and B.cereus were found different the MIC value of the water extract $(0.156 \mathrm{mg} / \mathrm{mL})$. The methanol extract of $S$. libanotica appeared to have moderate antimicrobial activity against S.aureus and B.cereus. MIC values of the water and methanol extract against other tested microorganisms were observed similar results (Table 3 ).

\section{Cell viability}

XTT (2,3-bis-(2-methoxy-4-nitro-5-sulfophenyl)-2Htetrazolium-5-carboxanilide) cell proliferation assay was used to evaluate the antiproliferative effects of the water and methanolic extracts of S. libanotica on MDA-MB-231 and L929 cell lines. As shown in Fig. 1, the methanol extract at 0.5 and $1 \mathrm{mg} / \mathrm{mL}$ concentration statistically significant inhibited MDA-MB-231 cell proliferation $(\mathrm{p}<0.05)$ in a dose-dependent manner $(\mathrm{IC} 50=0.67 \mathrm{mg} / \mathrm{mL})$. On the other hand, it has been found that the water extract has no cytotoxic effect at any concentration $(p>0.05)$. Furthermore, neither extract exhibited any significant cytotoxicity on the L929 cell line at the concentrations range $(1-0.0625 \mathrm{mg} / \mathrm{mL})$.

Our cytotoxicity results evidently showed that the methanol extract is more toxic than the water extract of $S$. libanotica. This may be because the methanol extract has richer active ingredients than the water extract, as shown in Table 1. Additionally, the anticancer effects may be associated with antioxidant features due to its polyphenolic components quantity (Fig. 1).

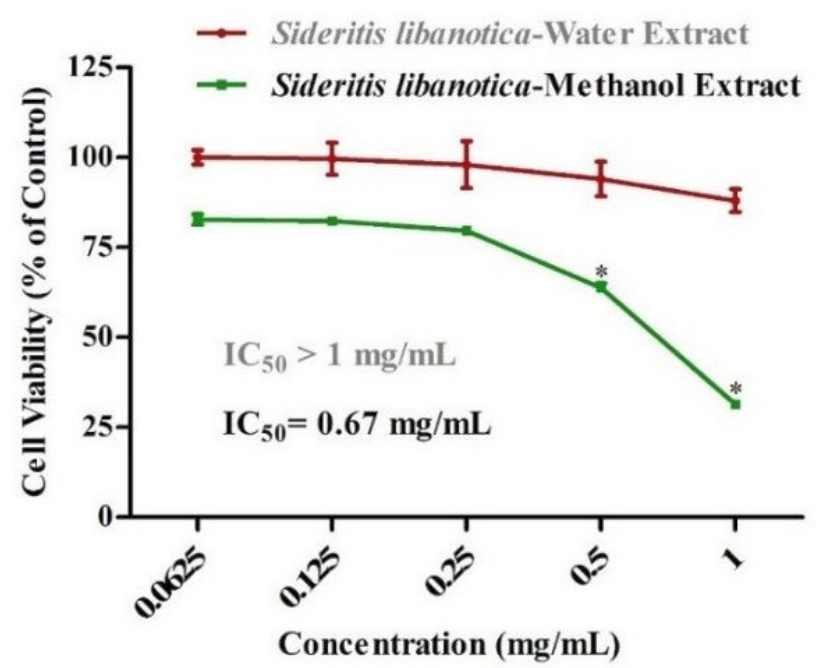

Fig. 1. Effects of the water and methanol extracts from $S$. libanotica on the viability of MDA-MB-231 cell line, after treatment with various concentrations (range: 0.065-1 $\mathrm{mg} / \mathrm{mL}$ ) for $24 \mathrm{~h}$. Both extracts show no toxicity in normal cells

Table 3. Antimicrobial activity results of S. libanotica extracts

Microorganisms and MIC Values $(\mathrm{mg} / \mathrm{mL})$

\begin{tabular}{ccccccc}
\hline & E.coli & S.aureus & P.aeruginosa & B.cereus & C.albicans & C.tropicalis \\
\cline { 2 - 5 } & ATCC 25922 & ATCC 29213 & ATCC 27853 & ATCC 11778 & ATCC 10231 & DSM 11953 \\
\hline $\begin{array}{c}\text { Water Extract } \\
\text { Methanol } \\
\text { Extract }\end{array}$ & 2.5 & 2.5 & 2.5 & 2.5 & 2.5 \\
\hline
\end{tabular}


216

\section{Conclusions}

In the present study, some biological activities including antioxidant, cytotoxicity, antimicrobial and various enzyme inhibition activities of the methanol and water extracts of the endemic $S$. libanotica have been investigated. It is also demonstrated the chemical content of extracts by using the GC-MS. The higher antioxidant activity of the methanol extract of $S$. libanotica can be correlated to the presence of more flavonoids and phenolic compounds of the methanol extracts than the water extracts. Additionally, the methanol extract shows better anti-cholinesterase activity and $\alpha$ glucosidase and $\alpha$-amylase inhibition activity than the water extract. However, an opposite situation was observed for tyrosinase inhibitory activities, i.e. the tyrosinase inhibitory activity of the water extract was found to be better than the methanol extract. Despite the intensive use of Sideritis species to relieve cold symptoms, antimicrobial efficacy of $S$. libanotica was found to be lower than expected. According to the cytotoxicity results, the methanol extract found to be more toxic than the water extract of $S$. libanotica. In conclusion, this study provides valuable information on how the biological activity of endemic S. libonitica changes in different solvent extractions such as water and methanol.

\section{Conflicts of interest}

The authors declare that there are no conflicts of interest related to this article.

\section{References}

Awouafack MD, McGaw LJ, Gottfried S, Mbouangouere R, Tane P, Spiteller M, EloffJN (2013). Antimicrobial activity and cytotoxicity of the ethanol extract, fractions and eight compounds isolated from Eriosema robustum (Fabaceae). BMC Complementary and Alternative Medicine 13(1):289.

Chacko LW, CerfJ (1960). Histochemical localization of cholinesterase in the amphibian spinal cord and alterations following ventral root section. Journal of Anatomy 94:7481.

Charles DJ (2013). Antioxidant properties of spices, herbs and other sources. Springer.New York, NY,USA pp 612

Clarke G, Ting K, Wiart C, Fry J (2013). High correlation of 2,2-diphenyl1-picrylhydrazyl (DPPH) radical scavenging, ferric reducing activity potential and total phenolics content indicates redundancy in use of all three assays to screen for antioxidant activity of extracts of plants from the malaysian rainforest. Antioxidants 42(1):1-10.

Clinical and Laboratory Standards Institute (2012). Methods for dilution antimicrobial susceptibility tests for bacteria that grow aerobically; approved standard-9th ed.CLSI document M07-A9. Clinical and Laboratory Standards Institute, Wayne,PA.

Čolović MB, Krstić DZ, Lazarević-Pašti TD, Bondžić AM, Vasić VM (2013). Acetylcholinesterase inhibitors: Pharmacology and toxicology. Current Neuropharmacology 11(3):315-335.

Davis PH (1982). Flora of Turkey and the East Aegean Islands. Edinburgh University Press, Vol7, Edinburgh.

Davis PH, Mill RR, Tan K (1988). Flora of Turkey and the East Aegean
Islands. Vol 10 (Suppl 1) Edinburgh: Edinburgh University Press pp 324326.

Demirtas I, Ayhan B, Sahin A, Aksit H, Elmastas M, Telci I (2011). Antioxidant activity and chemical composition of Sideritis libanotica Labill. ssp. linearis (Bentham) Borm. (Lamiaceae). Natural Product Research 25(16):1512-1523.

Deveci E, Tel Çayan G, Duru ME (2018). Phenolic profile, antioxidant, anticholinesterase, and anti-tyrosinase activities of the various extracts of Ferula elaeochytris and Sideritis stricta. International Journal of Food Properties 21(1):771-783.

Deveci E, Tel Çayan G, Ylldırm H, Duru ME (2017). Chemical composition, antioxidant, anticholinesterase and anti-urease activities of Sideritis pisidica Boiss. \& Heldr. endemic to Turkey. Marmara Pharmaceutical Journal 21(4):898-905.

Dincer C, Torun M, Tontul I, Topuz A, Sahin Nadeema H, Gokturk RS, Tugrul AS, Ozdemir F (2017). Phenolic composition and antioxidant activity of Sideritis lycia and Sideritis libanotica subsp. linearis: Effects of cultivation, year and storage. Journal of Applied Research on Medicinal and Aromatic Plants 5:26-32.

Ellman GL, Courtney KD, Andres V, Featherstone RM(1961). A new and rapid colorimetric determination of acetylcholinesterase activity. Biochemistry Pharmacology 7(2):88-95.

EloffJN (1998). A sensitive and quick microplate method to determine the minimal inhibitory concentration of plant extracts for bacteria. Planta Medica 64(8):711-713.

Giacobini E (2003). Cholinesterases: New roles in brain function and in Alzheimer's disease. Neurochemical Research 28(3-4):515-22.

Giacobini E (2004). Cholinesterase inhibitors: new roles and therapeutic alternatives. Pharmacology Research 50(4):433-40.

González Burgos E, Carretero M, Gómez Serranillos M (2011).Sideritis spp:: uses, chemical composition and pharmacological activities-a review.Journal ofEthnopharmacology 135(2):209-225.

Henrissat B (1998). Glycosidases families. Biochemical Society Transactions 26:153-156.

Jeong SH, Ryu YB, Curtis-Long MJ, Ryu HW, Baek YS, Kang JEl (2009). Tyrosinase inhibitory polyphenols from roots of Morus Ihou. Journal of Agricultural and Food Chemistry 57(4):1195-1203.

Kargioglu M, Cenkci S, Serteser A, Evliyaoğlu N, Konuk M, Şamil Kök M, Bagci Y (2008). An ethnobotanical survey of inner-west Anatolia, Turkey.Human Ecology 36(5):763-77.

Kimura A (2000). Molecular anatomy of $\alpha$-glucosidase. Trends in Glycoscience and Glycotechnology 12:373-380.

Koelle GB (1954). The histochemical localization of cholinesterases in the central nervous system of the rat. Journal of Comparative Anatomy 100(1):211-235.

Korkmaz K, Kara SM, Özkutlu F, Akgün M, Cenkal BC (2017). Profile of heavy metal and nutrient elements in some sideritis species. Indian Journal of Pharmaceutical Education and Research 51(3):209-212.

Korkmaz S, Atasoy N, Turoglu V, Yucel U (2017). Investigation of in vitro effects of polar and nonpolar extracts of mountain tea plant (Sideritis libanotica subsp. linearis Labil) on acetylcholinesterase enzyme within human serum and erythrocytes. Fresenius Environmental Bulletin 26:4163-4169. 
Kuete V (2010) Potential of Cameroonian plants and derived products against microbial infections: a review. Planta Medica 76(14):1479-1791.

Kumar D, Gupta N, Ghosh R, Gaonkar RH, Pal BC (2013). a-Glucosidase and $\alpha$-amylase inhibitory constituent of Carex baccans: Bio-assay guided isolation and quantification by validated RP-HPLC-DAD. Journal of Functional Foods 5(1):211-218.

Kumar D, Kumar H, Vedasiromoni JR, Pal BC (2012). Bio-assay guided isolation of $\alpha$-glucosidase inhibitory constituents from Hibiscus mutabilis leaves. Phytochemical Analysis 23(5):421-425.

Lane RM, Potkin SG, Enz A (2006). Targeting acetylcholinesterase and butyrylcholinesterase in dementia. International Journal of Neuropsychopharmacology 9(1):101-124.

Miser-Salihoglu E, Akaydin G, Caliskan-Can E, Yardim-Akaydin S (2013). Evaluation of antioxidant activity of various herbal folk medicines. Journal of Nutrition Food Sciences 3:222.

Molan AL, Mahdy AS (2014). Iraqi medicinal plants: Total flavonoid contents, freeradical scavenging and bacterial beta-glucuronidase inhibition activities. ISOR Journal of Dental and Medical Sciences 13:72-77.

National Committee for Clinical Laboratory Standards(2002). Reference method for broth dilution antifungal susceptibility testing of yeasts; approved standard. Second edition, document M27-A2. National Committee for Clinical Laboratory Standards, Wayne, PA.

Patra K, Jana S, Mandal DP, Bhattacharjee S (2016). Evaluation of the antioxidant activity of extracts and active principles of commonly consumed Indian spices.Journal of Environmental Pathology, Toxicology and Oncology 35(4):299-315.

Pohanka M (2011). Cholinesterases, a target of pharmacology and toxicology. Biomedical Papers 155(3):219-29.

Polat R, Satil F (2012). An ethnobotanical survey of medicinal plants in Edremit Gulf (Balkesir - Turkey).Journal of Ethnopharmacology 139(2):626-641.

Proenca C, Freitasa M, Ribeiro D, Oliveira EF, Sousa JL, Tome SM (2017). $\alpha$-Glucosidase inhibition by flavonoids: An in vitro and in silico structure-activity relationship study.Journal of Enzyme Inhibition and Medicinal Chemistry32(1):1216-1228.

Re R, Pellegrini N, Proteggente A, Pannala A, Yang M, Rice-Evans C (1999).Antioxidant activity applying an improved abts radical. Free Radical Biology Medicine 26(9-10):1231-1237.

Sacchetti G, Maietti S, Muzzoli M, Scaglianti M, Manfredini S, Radice M, Bruni R (2005). Comparative evaluation of 11 essential oils of different origin as functional antioxidants, antiradicals and antimicrobials in foods. Food Chemistry 91(4):621-632.
Salah NM, Souleman AMA, Shaker KH, Hawary SE, El-Hady FKA (2017). Acetylcholinesterase, alpha-glucosidase and tyrosinase inhibitors from Egyptian propolis. International Journal of Pharmacognosy Phytochemistry Research 9:528-536.

Sama NA, Mahmood MR, Muhamad S (2014). The role of nanotechnology application in antioxidant from herbs and spices for improving health and nutrition: A review. Selangor Science and Technology Review 1(1):17-23.

Schmeda-Hirschmann G, Yesilada E (2005). Traditional medicine and gastroprotective crude drugs. Journal of Ethnopharmacology 100(1):6166.

Svensson B (1988). Regional distant sequence homology between amylases, $\alpha$-glucosidases and transglucanosylases. FEBS Letters 28:230(1-2):7276.

Tadić VM, Jeremic I, Dobric S, Isakovic A, Markovic I, Trajkovic V, Bojovic D, Arsic I (2012). Anti-inflammatory, gastroprotective, and cytotoxic effects of Sideritis scardica extracts. Planta Medica 78(05):415-427.

Tepe B, Sökmen M, Akpulat HA, Yumrutaş Ö, Sökmen A (2006). Screening of antioxidative properties of the methanolic extracts of Pelargonium endlicherianum Fenzl., Verbascum wiedemannianum Fisch. \& Mey., Sideritis libanotica Labill. subsp. linearis (Bentham) Borm., Centaurea mucronifera DC., and Hieracium cappadocicum Freyn. from Turkish flora. Food Chemistry 98(1):9-13.

TruscheitE, Frommer W, Junge B, Mueller L, Schmidt DD, Wingender W (1981). Chemistry and biochemistry of microbial a-glucosidase inhibitors. Angewandte Chemie International Edition (English) 20(9):744761.

Tundis R, Loizzo MR, Menichini F (2010). Natural products as $\alpha$-amylase and $\alpha$-glucosidase inhibitors and their hypogycaemic potential in the treatment of diabetes: an update. Mini-Reviews in Medicinal Chemistry 10(4):315-331.

Yamamoto T, Unno T, Watanabe Y, Yamamoto M, Okuyama M, Mori H, Chiba S, Kimura A (2004). Purification and characterization of Acremonium implicatum $\alpha$-glucosidase having regioselectivity for $\alpha-1,3$ glucosidic linkage. Biochimica et Biophysica Acta 2 1700(2):189-98.

Yashin A, Yashin Y, Xia X, Nemzer B (2017). Antioxidant activity of spices and their impact on human health: A review. Antioxidants 6(3):70. 